\title{
A Democracia no Âmbito do Conselho de Segurança das Nações Unidas ${ }^{1}$
}

The Democracy in the Scope of the UN Security Council

\section{Ana Paula Canarines ${ }^{2}$}

\section{RESUMO}

Para combater a crise de legitimidade pela qual as OIs têm passado é imprescindível entender a otimização gerada pela adoção dos mecanismos institucionais, como transparência e accountability. No contexto do Conselho de Segurança, a partir de uma breve análise bibliográfica, é possível apontar que, apesar das tentativas de melhoria, se faz necessário adotar medidas mais efetivas para alcançar a democratização e a legitimidade almejadas.

Palavras-chave: Democracia; Mecanismos Institucionais; Conselho de Segurança.

\begin{abstract}
To fight against the legitimacy crisis whereby IOs have past it is essential to understand the improvement created by adoption of institutional mechanisms, such as transparency and accountability. In the context of the Security Council, as of a brief bibliographic analysis, it is possible to point out that, despite of attempts to improvement, it is necessary to adopt measures that are more effective to achieve the intended democratization and legitimacy.

Key-words: Democracy; Institutional Mechanisms; Security Council.

\section{Introdução}

A defesa da instituição da democracia como forma de governo é um assunto recorrente na agenda internacional de vários países e é frequentemente debatida nos Conselhos da ONU. Um dos temas mais recentes é o andamento da chamada Primavera

\footnotetext{
${ }^{1}$ Artigo recebido em 20 de dezembro de 2013 e aceito para publicação em 02 de fevereiro de 2014.

2 Graduanda em Relações Internacionais pelo Centro Universitário UNINTER, em Curitiba/PR, Brasil.

E-mail: ana.canarines@gmail.com

Conjuntura Global, Curitiba, Vol.2, n.4, out./dez., 2013, p. 237-243.
} 
Árabe. Superficialmente pode-se dizer que a Primavera Árabe foi um conjunto de manifestações e revoltas populares ocorridas em alguns países do Norte da África e do Oriente Médio, como Egito e Síria. Essas manifestações buscavam derrubar os governos autoritários que comandavam os países e instaurar uma nova forma de governo.

A agitação nos Conselhos da ONU durante esse período de revoluções foi notável. Com as devidas aprovações, a Organização enviou equipes de socorro humanitário - como no caso da Líbia - e de mediação para promover a paz e uma transição para um regime democrático.

Entretanto, apesar da predisposição da ONU em disseminar os ideais democráticos pelo mundo, o regimento interno de seus Conselhos não se dá dessa forma. A partir dessa premissa, este artigo pretende abordar o tema da democracia no âmbito do Conselho de Segurança da ONU, mais especificamente, o processo de democratização que vem sendo reivindicado por alguns Estados ao longo dos últimos anos, pois segundo Pereira, "o CSNU não seria compatível com a própria natureza da democracia" (PEREIRA, 2013, p. 119).

O objetivo principal, porém, será buscar uma resposta para o questionamento: como a atuação dos mecanismos institucionais - principalmente a transparência e a accountability - contribui para a democratização e a legitimidade do Conselho de Segurança da ONU?

A discussão desse tema se faz importante devido à atualidade do debate e ao destaque que ele vem ganhando na Agenda Internacional de muitos países, dentre eles o Brasil e o grupo de coalizão do qual faz parte, o G-4. Assim sendo, este artigo está didaticamente estruturado em seções, sendo a subsequente dividida em três áreas: o item 2.1 é destinado à discussão do conceito de democracia que será adotado para fins deste artigo; no item 2.2 é feita uma análise democrática do Conselho de Segurança; e no item 2.3 será discutida a atuação dos mecanismos institucionais de democratização, a saber: as ações "voltadas para o incremento de sua transparência e da sua accountability" (PEREIRA, 2012, p.4). Na seção 3 serão apresentadas algumas conclusões relativas ao tema. 


\section{Democracia no âmbito do Conselho de Segurança da ONU}

\section{DEFINIÇÃO DE DEMOCRACIA}

Para fins deste artigo, serão adotados alguns pontos da definição de Robert Dahl a respeito da democracia, ou seja, será adotada uma abordagem minimalista. Entretanto, é preciso ressaltar que a questão da democracia no CSNU será debatida apenas no âmbito de seu funcionamento interno, sem menção as características democráticas inerentes a participação "externa" da sociedade internacional.

Segundo o autor, a democracia é caracterizada por proporcionar, no funcionamento das instituições, oportunidades para que haja participação efetiva dos membros bem como igualdade de voto, inclusão, disponibilidade de informações e controle de planejamento. Nesse sentido, o autor considera a democracia como um ideal a ser perseguido pelas sociedades de grande escala existentes no século XX, mas não como regime político realmente existente. Há apenas um "tipo moderno de governo democrático em grande escala [que] às vezes é chamado de poliarquia - democracia poliárquica" (DAHL, 2001, p. 104), de acordo com o seguimento de alguns requisitos e com seu grau de inclusão e tolerância.

Para a análise democrática das Organizações Internacionais, é preciso fazer algumas adaptações à teoria de Dahl, visto que elas estão sujeitas as configurações anárquicas do sistema internacional, possuem limitações de governança e não têm as mesmas configurações de administração dos Estados, como no caso do Conselho de Segurança das Nações Unidas.

\section{O CONSELHO DE SEGURANÇA}

A Organização das Nações Unidas (ONU) foi criada após a Segunda Guerra Mundial como uma instituição supranacional que tem o intuito de manter a paz mundial nos diversos âmbitos de relacionamento entre os países. O Conselho de Segurança das Nações Unidas (CSNU) é um de seus principais Conselhos e é o único que possui poder decisório, ou seja, todos os países membros das Nações Unidas, independente do órgão em que participam, devem acatar e cumprir suas decisões. 
Criado 1945 com o principal objetivo de garantir a "paz e a segurança internacionais" (ONU Brasil), o CSNU gerencia conflitos entre as nações para evitar a ocorrência de uma Terceira Guerra Mundial. Desde 1946, quando houve sua primeira intervenção oficial, até os mais recentes conflitos, como as revoluções da Primavera Árabe, acima citados, o Conselho atua com o envio de Missões de Paz aos locais de conflito, com a elaboração de planos de regulamentação de armamentos e com o monitoramento de ameaças à paz, dentre outras funções.

O CSNU é formado por 15 membros, sendo cinco permanentes (Estados Unidos, Grã-Bretanha, Rússia, China e França) e dez não-permanentes, que são eleitos pela Assembleia Geral e possuem mandatos de dois anos. A formatação institucional do Conselho nunca sofreu alterações, sendo que essa configuração está vigente desde 1945. Os cinco membros permanentes são os únicos que possuem, durante as votações nas reuniões, direito a veto.

Antes de abordar os mecanismos de democratização do CSNU é preciso destacar alguns pontos que tornam esse órgão não democrático. Seguindo as diretrizes de Dahl, percebe-se, primeiramente, a ausência da igualdade de voto entre os membros do Conselho. Conforme descrito acima, somente os membros permanentes possuem direito a veto, sendo que os outros membros, mesmo que tenham a maioria na votação, não poderão aprovar uma proposta se algum dos cinco países vetar. Outro ponto é a questão da inclusão: a limitação da quantidade de países membros no CSNU fere o princípio da inclusividade, pois somente 15 dos 193 Estados-membros da ONU são participantes.

Por fim, a disponibilidade e a transparência das informações também são pontos questionáveis e serão tratados a seguir como parte dos mecanismos de democratização citados por Pereira (2012). Essa questão também é abordada na Nota do Presidente da ONU e está ligada a institucionalização da accountability apresentada por Grant e Keohane.

\section{MECANISMOS DE DEMOCRATIZAÇÃO DO CONSELHO DE SEGURANÇA}

A transparência e a accountability vem sendo discutidas, nos últimos anos, como ferramentas de relevância para combater problemas recorrentes nas Organizações Internacionais, como a questão da legitimidade e da eficácia das ações, que decorrem, Conjuntura Global, Curitiba, Vol.2, n.4, out./dez., 2013, p. 237-243. 
dentre outros motivos, das falhas democráticas dessas instituições. O CSNU, como órgão da ONU, também está sujeito à essas falhas, conforme descrito acima, e carece da adoção de melhorias para garantir sua legitimidade no cenário internacional.

Nesse sentido, Grant e Keohane apresentam a institucionalização dos mecanismos de accountability como um requisito sine qua non para o processo de democratização e legitimação das ações do Conselho de Segurança. Em suas palavras, "accountability [...] implies that some actors have the right to hold other actors to a set of standards, to judge whether they have fulfilled their responsibilities in light of these standards, and to impose sanctions if they determine that these responsibilities have not been met"3 (GRANT, 2005, p. 29), ou seja, alguns atores podem impor ao demais certos padrões e responsabilidades que deverão ser cumpridas e no caso de transgressão, esses atores poderão aplicar sanções.

A accountability implica na capacidade do ator que tomou a decisão ser responsabilizado por ela perante os demais e, para isso, é preciso conhecer as negociações que levaram a tomada de decisão. Dessa forma, apesar de não ocorrer uma responsabilização perante um público global, considerado inexistente pelos autores, há a justificação das decisões. No caso do Conselho de Segurança, essa prestação de contas se faz perante os Estados-membros da ONU. Institucionalizar mecanismos de accountability é, então, uma forma de garantir, além de maior visibilidade às atividades do Conselho, maior legitimidade às suas decisões e, consequentemente aprimorar o desenho institucional democrático dos órgãos componentes das Nações Unidas.

É importante ressaltar que o próprio Conselho vem debatendo formas para melhorar a transparência das informações pertinentes ao seus processos e ações. $\mathrm{Na}$ nota do presidente do CSNU de 19 de julho de 2006, estão reunidas algumas medidas acordadas pelos membros do Conselho que visam concretizar essas ideias. Dentre elas, destacam-se a necessidade de o presidente do Conselho de Segurança oferecer informações mais detalhadas aos Estados membros que possam subsidiar de maneira mais satisfatória suas decisões; e a realização de mais reuniões públicas, que incluam,

\footnotetext{
${ }^{3}$ Accountability [...] implica que alguns atores têm o direito de submeter outros atores a um conjunto de normas, de julgar se eles têm cumprido suas responsabilidades à luz dessas normas e de impor sanções se determinarem que essas responsabilidades não tenham sido cumpridas. (Tradução livre)

Conjuntura Global, Curitiba, Vol.2, n.4, out./dez., 2013, p. 237-243.
} 
por exemplo, debates abertos para exposição de informações referentes ao temas discutidos.

Apesar disso, Pereira (2012) salienta que essas medidas ainda são muito incipientes e não influenciam na resolução de problemas essenciais do processo decisório, como a questão do veto dos membros permanentes. A adoção de medidas efetivas se faz necessária para o real progresso no sentido da democratização do Conselho e "da adequação das organizações internacionais [principalmente da ONU] às novas demandas que caracterizam a cena internacional contemporânea" (PEREIRA, 2012, p. 28). Porém, como elas seriam resultado de um processo político que não beneficiaria os interesses daqueles que possuem o direito de veto e os privilégios de informação, a discussão tende a se prolongar sem resultados definitivos.

\section{Conclusão}

Este artigo buscou compreender a atuação dos mecanismos de democratização no Conselho de Segurança da ONU. Nesse sentido, pôde-se perceber que instrumentos como a transparência e a accountability contribuem como marco inicial para a conquista de um ambiente mais democrático nas Organizações Internacionais. Apesar das limitações que estas instituições supranacionais possuem devido a configuração do sistema internacional é preciso garantir um progresso, mesmo que lento, no sentido da democracia institucional, conforme definição estabelecida no item 2.1 - Definição de Democracia.

As tentativas do próprio Conselho, registradas na Nota do Presidente do CSNU em 2006, revelam uma pré-disposição, embora tímida, à otimização de sua atuação. Porém, conforme sinalizou Alexsandro Pereira (2012) ainda há uma gama de medidas a serem tomadas para que a atuação das OIs, principalmente as ações dos órgãos da ONU, ganhe mais legitimidade e efetividade. 


\section{Referências Bibliográficas}

DAHL, Robert. Sobre a democracia. Brasília: UNB, 2001, p. 97-113. Disponível em: <http://www.saudebucalcoletiva.unb.br/ensino/introducao_a_ciencia_ politica/23_Dalh_Sobre_a_Democracia.pdf> Acesso em: 22/11/13

GRANT, Ruth W. and KEOHANE, Robert. Accountability and Abuses of Power in World Politics. The American Political Science Review, vol. 99, no 1, February 2005, p. 2943. Disponível

em: <http://www.princeton.edu/ rkeohane/publications/apsr_abuses.pdf > Acesso em: $20 / 11 / 13$

NOTA do Presidente do Conselho de Segurança da ONU, 19/07/2006. (S/2006/507) Disponível em: <http://www.un.org/en/sc/repertoire/Notes/s-2006-507.pdf> Acesso em 20/11/13

ONU Brasil. Como funciona?Disponível em $<$ http://www.onu.org.br/conheca-aonu/como-funciona/> Acesso em 20/11/13

PEREIRA, Alexsandro Eugênio. Transparência, Legitimidade e Democracia: o Conselho de Segurança da ONU na primeira década dos anos 2000. 36ํㅡㄹ Encontro Anual da ANPOCS, 2012. Disponível em: $<$ http://www.google.com.br/url?sa=t\&rct=j\&q=\&esrc=s\&source=web\& $\mathrm{cd}=1 \& \mathrm{cad}=$ rja\&ved=0CC8QFjAA\&url=http $\% 3 \mathrm{~A} \% 2 \mathrm{~F} \% 2 \mathrm{Fw} w \mathrm{w} \cdot$ anpocs.org $\% 2 \mathrm{Fportal}$ \%2Findex.php\%3Foption\%3Dcom_docman\%26task\%3Ddoc_download\%26gid\%3 D8161\%26Itemid\%3D76\&ei=Nd2MUpjOCM_S2wXXuIHoCg\&usg=AFQjCNF6gGez43 crdw8Uo0naCWVr_XSp4A\&sig2=7Dv1qgBvW2eUqtkCt_Or3Q\&bvm=bv.56643336,d .b2I> Acesso em: 20/11/13

. A Reforma do Conselho de Segurança da ONU: Notas Preliminares. Conjuntura Global, Curitiba, Vol. 2, n.3, jul./set., 2013, p. 117-121. Disponível em: <http://www.humanas.ufpr.br/portal/conjunturaglobal/files/2013/04/ AReforma-do-Conselho-de-Seguran\%C3\%A7a-da-ONU-Notas-Preliminares.pdf> Acesso: $20 / 11 / 13$ 